Article

\title{
The Role of African Emerging Space Agencies in Earth Observation Capacity Building for Facilitating the Implementation and Monitoring of the African Development Agenda: The Case of African Earth Observation Program
}

\author{
Mahlatse Kganyago * (D) and Paidamwoyo Mhangara \\ Earth Observation Directorate, South African National Space Agency (SANSA), The Enterprise Building, \\ Mark Shuttleworth Street, Pretoria 0002, South Africa \\ * Correspondence: mkganyago@sansa.org.za
}

Received: 30 April 2019; Accepted: 15 June 2019; Published: 27 June 2019

\begin{abstract}
AU-Agenda 2063 was adopted at the 24th Ordinary Session of the African Heads of State and Government in 2015 as the blueprint for the future development of the continent. Built upon the continent's past experiences, challenges, and successes, AU-Agenda 2063 comprehensively describes the strategic path for Africa's future development in the next 50 years. Thus, the monitoring of its implementation in various African states is critical for ensuring sustainable development and track progress. However, the higher cost of collecting data for accurately and reliably monitoring the implementation of Agenda 2063 may hinder the progress towards achieving these goals. Satellite Earth observation provides ample data, and thus has provided opportunities for the development of novel products and services with the potential to support implementation, monitoring and reporting for AU-Agenda 2063 development imperatives. However, it has been limitedly exploited in Africa, as evidenced by lower research outputs and investments. This calls for increased capacity building in the use of available EO data and products for various users including decision makers to advance national, regional and continental priorities. The use of such data products is often hampered by the capability to understand the products and thus their value for addressing socio-economic challenges. This paper discusses the potential of Earth observation capacity building for supporting the implementation, monitoring of, and reporting towards achieving AU-Agenda 2063 development imperatives. Specifically, this paper identifies existing capacity building resources, including the role of open and free Earth observation data, open-source software, and product dissemination platforms that can be leveraged for supporting national development, service delivery and the achievement of AU-Agenda 2063 targets. Furthermore, the paper recognizes the importance of bilateral and multilateral partnerships in leveraging existing know-how, technology and other resources for advancing strategic goals of African emerging space agencies and promoting sustainable development, with examples from South African National Space Agency (SANSA). Then, the challenges and opportunities for capacity building and the wide adoption of EO in Africa are discussed in the context of AU-Agenda 2063. The paper thus concludes that EO capacity building is essential to address the skills and data gaps and increase the use of EO-based solutions for decision making in various sectors, critical for achieving AU-A2063.
\end{abstract}

Keywords: AU-Agenda 2063; Capacity building; Earth observation; UN-SDGs 


\section{Introduction}

\subsection{Background}

Developing countries are faced with a plethora of challenges, including the provision of basic needs such as food, shelter, water and sanitation, health care, quality education, and a clean and healthy environment, exacerbated by exponentially growing populations, the prevalence of diseases, and a changing climate. In particular, Africa faces challenges such as rising populations, extreme poverty, the proliferation of diseases, conflicts, and food shortages, among others. Global efforts are underway to address some of the major challenges in Africa and the world, such as eradication of poverty, proper sanitation for all, education of women and children, sustainable forests and natural resources, increase agricultural productivity, etc. These are embedded in the Global Agenda, i.e., the United Nations (UN) 2030 Sustainable Development Goals (SDGs), and global policy mandates, such as Paris Agreement on Climate Change and Sendai Framework for Disaster Risk Reduction. In 2015, the African Heads of State and Government adopted the African Union (AU) Agenda 2063 [1] as the blueprint for future development of the continent, based on previous experiences and programs such as the Lagos Plan of Action [2], the Abuja Treaty and the New Partnership for Africa's Development (NEPAD). AU-Agenda 2063 outlines seven (7) aspirations, 20 goals and 140 indicators for Africa's sustainable development. The First-Ten-Years Implementation Plan (FTYIP) sets targets for the first ten years of implementation (i.e., 2014-2023) and indicates alignment with UN-SDGs indicators in order to reduce the level of reporting by member states. Among the many challenges facing Africa, the eradication of poverty (reducing unemployment rate) and hunger (doubling agricultural production), access to safe drinking water, health and infrastructure, and accelerating economic growth are some of the key foci of the AU-Agenda 2063. Achieving these requires a concerted effort (i.e., multi-sectoral partnerships), improvement of institutional and human capacities, alignment of national priorities to the AU-Agenda 2063 goals and targets, and timely and accurate information to support implementation, progress monitoring and reporting.

Generally, Africa can be considered a data-scarce continent [3-5], with only a few member states being actively involved in consistent and systematic data collection activities through census and household surveys. These inarguably constitute the most detailed and accurate statistical information about the population and household well-being, critical for planning, allocation of resources, supporting national policy and decision-making related to the provision of health facilities, housing, and other amenities. However, due to the excessive cost of conducting such census and household surveys, scattered populations, security concerns, etc., most African countries are unable to provide accurate and reliable data at the required intervals and frequencies to support policy and decision-making. In addition, the effects of anthropogenic climate change on the environment are gradual, while disasters such as floods are too sudden to be surveyed by traditional methods. As a result, the lack of accurate and adequate information may result in loss of life, and deter the progress towards achievement of sustainable development and economic growth. Earth observation (EO) satellites have the capability to frequently collect data about the Earth, covering large areas, in sufficient detail and can overcome limitations of traditional surveys. Additionally, several tangible socioeconomic benefits of earth observation and geospatial technologies have been reported around the world. These include, among others, monitoring land use change, managing disease outbreaks, optimizing agricultural production, early warning and impact assessment of disasters such as floods, drought, and bushfires, tracking biodiversity trends and contributing to the sustainable management of agricultural, fresh water and energy resources [6]. A demonstration of how some of these applications can address AU-Agenda 2063 is given in Figure 1. Although it has not been fully exploited in Africa, most African countries are increasingly adopting EO and Geospatial technologies to support their sustainable development agendas and addressing data gaps. An increasing recognition of, and investment in, space technologies, including EO, is evidenced by several African countries, including Nigeria, Egypt, Algeria, Kenya, South Africa, and Gabon, who have established their own space agencies and/or successfully launched 
their own Earth observation satellites since the beginning of the 21st century. In addition, there is increasing political will and awareness, as evidenced by the recent (in 2017) adoption of African Space Policy and Strategy, aimed at coordinating and driving the African space program, which is responsive to the socioeconomic, political and environmental challenges, as well as the sustainable development aspirations of the continent as set out in AU-Agenda 2063. In addition, most countries participate in the African Group on Earth Observations (AfriGEO) initiative to access and leverage EO-based activities on the continent.

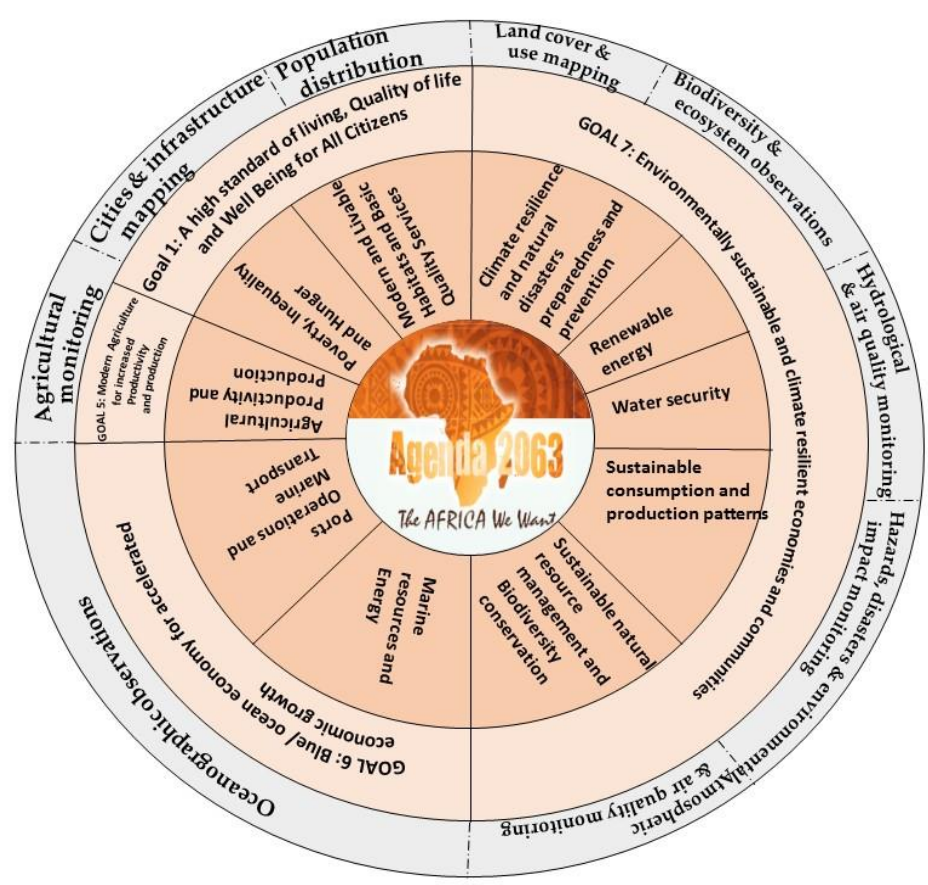

Figure 1. AU-Agenda 2063 First-Ten-Years Implementation Plan (FTYIP) priority areas and goals (first and second rings, respectively) that can be directly addressed by common Earth observation applications (outer ring).

The success and sustainability of African emerging space agencies will in part be predicated on the scientific and technical expertise and competencies of their employees and users. Indeed, one of the key objectives highlighted in the African Space Policy is the development of the requisite human capital through existing institutions and infrastructure, which is critical to ensuring the widespread exploitation and use of space technologies. To advance this objective, the AU has identified the need to establish a Pan-African University on Space Science and Technology in South Africa that is aimed at providing advanced graduate training and research for African students. Apart from formal education and training through degree programs, development of human capital through capacity building is a critical component to the marketing of EO data, products and services in order to ensure wider use and increase self-sufficiency and access to information [7]. Essentially, the achievement of most African Space Policy objectives, such as addressing user needs, accessing space services, developing the regional market, adopting good governance and management, and promoting intra-Africa and other international cooperation hinges on robust capacity building in EO. Therefore, increasing the use of EO by specialists, students, researchers, professionals from various disciplines and decision makers through capacity building should be the main priority of emerging space agencies and similar institutions in order to take advantage of multiple immediate and downstream benefits of $\mathrm{EO}$, which is critical for supporting national development plans, government mandates, legislative acts and regulations, policy and decision making as well as realizing AU-Agenda 2063 aspirations. These space agencies are well-positioned to address the multifaceted challenges of the continent. 
The South African National Space Agency (SANSA), an entity of Department of Science and Technology (DST), is mandated by the South African Space Agency Act, 36 of 2008, and National Space Strategy [8], to coordinate and integrate space science and technology programs, conduct long-term planning and implementation of space-related innovations in South Africa, and ensure the supply of cost-effective space-based EO data and products to support South Africa's policy, decision-making, economic growth and sustainable development. The agency fosters research in space science, communications, navigation and space physics, and it advances scientific, engineering and technological competencies and capabilities through human capital development, outreach activities and infrastructure development, and fosters international co-operation (including with other African organizations) in space-related activities. The Earth Observation Program of SANSA aims to coordinate South Africa's Earth observation activities. The main objectives are to collect, archive, assimilate and disseminate earth observation data over the Southern African region to support policy, decision-making and sustainable economic growth in the country and the region. Its impact is in providing, among other things, essential EO data and services, including value-added products and services to state-owned departments, the private sector and other Small and Medium Enterprises (SME), and supporting EO research and application development, as well as human capital development and outreach activities. Thus, through the provision of EO data, products and services, SANSA is supporting several legislative acts and regulations, e.g., the Conservation of Agricultural Resources Act No. 43 of 1983, Water Services Act No. 108 of 1997, National Water Act No. 36 of 1998, National Environmental Management (NEM): Biodiversity Act No. 10 of 2004, NEM: Protected Areas Act No. 57 of 2003, Spatial Planning and Land Use Management Act No.16 of 2013, Disaster Management Act No. 57 of 2002, and South Africa's Vision 2030 (also known as the National Development Plan 2030), among others. Among SANSA's five strategic goals, human capital development has been highlighted as cross-cutting and integral to the success of the South African Space Program. To achieve this objective, SANSA uses several collaborative capacity building approaches to advance skills development on the African continent. Its multi-pronged approach includes funding of post-graduate students, short training courses, supervision of postgraduate students, guest lecturing at universities, internships and studentship programs.

\subsection{Scope and Objectives of the Study}

Unfortunately, only a few studies have discussed the role of Earth observation in the context of capacity building in Africa for addressing service delivery and national development as well as AU-Agenda 2063 development imperatives. In addition, existing EO-derived information in various thematic applications and open and free satellite data and software are underutilized, attributable to lack of awareness, technical capability, and infrastructure for processing, analyzing, storing and disseminating terabytes of data. Therefore, this paper seeks to address these gaps, by discussing the potential of capacity building in Earth observation for supporting the implementation, monitoring of, and reporting for, AU-Agenda 2063 development imperatives. Specifically, we identified existing capacity-building resources, including the role of open and free Earth observation data, open-source software, and product dissemination platforms that can be leveraged for supporting national development, service delivery and the achievement of AU-Agenda 2063 targets. Furthermore, the paper recognizes the importance of bilateral and multilateral partnerships in leveraging existing expertise, technology and other resources for advancing strategic goals of African emerging space agencies and promoting sustainable development with examples from South African National Space Agency (SANSA). Then, the challenges and opportunities for capacity building and wide adoption of EO in Africa are discussed in the context of African emerging space agencies and AU-Agenda 2063.

\section{Earth Observation Data for Capacity Building}

For decades, Earth observation satellites have produced a comprehensive archive of data covering the entire globe. Specifically, satellites such as the Advanced Very High-Resolution Radiometer 
(AVHRR), MERIS, MSG Geostationary satellite, and Moderate Resolution Imaging Spectroradiometer (MODIS) provide wide coverage, allowing daily image acquisitions at a coarse spatial resolution of between $250 \mathrm{~m}$ and $1 \mathrm{~km}$. These course resolution datasets have been invaluable in developing global land cover products such as GlobCover [9,10], Global Land Cover 2000 [11], DISCover [12] and MODIS Land Cover [13,14], among others. In addition, the datasets have been used for mapping, monitoring and assessment of wildfires [15-17], surface water [18-20], floods [21,22], agricultural activities [23-25], biodiversity [26-28], and drought [29,30]. These datasets provide unparalleled, temporally detailed information that is useful for rapid detection of surface changes due to various natural and anthropogenic phenomena such as disasters and land-use changes; thus, they are suitable for addressing information needs at national to regional scales, to support implementation, monitoring and reporting at these levels. However, detailed analysis and monitoring for decision making at a local scale require high spatial resolution.

The availability of long-term, medium-resolution data records and almost continuous coverage since 1972 from the Landsat program have unequivocally advanced research, products and applications development in an unprecedented manner. Alarmingly, studies show that research outputs from African institutions are still low, which is attributable to insufficient internet bandwidth for downloading satellite data and a lack of hardware for processing, analyzing and storing the data. Landsat's wealth of data is sustained by the availability of new-generation advanced sensors such as Landsat 8 Operational Land Imager (OLI), CBERS-4B and Sentinel 2 Multispectral Imager (MSI), with better spatial, temporal and spectral resolutions, accessible from various data catalogues (Figure 2). These offer profound opportunities for capacity building in Earth observations and the development of innovative commercial solutions and applications in various thematic areas that are relevant for addressing AU-A2063 aspirations. In addition to being the greatest asset to global change studies, data from Landsat and Sentinel 2 are valuable for monitoring and assessment at a landscape scale to support on-the-ground decisions and enhancing service delivery. The increase in free and open data presents new challenges that require new techniques to fuse multiple datasets to take advantage of their unique characteristics related to spatial and temporal resolutions, and to overcome challenges related to clouds and associated cloud shadows common in EO data. Fortunately, data infrastructures such as Data Cube (also known as Digital Earth) offer prospects for sustainable development in Africa. This is evidenced by initiatives focusing on Africa such as African Regional Data Cube [31] (ARDC) and Digital Earth Africa [32].

In addition, commercial data from sensors such as from SPOT 6/7, Rapid Eye and Worldview are increasingly becoming affordable, with the capability for user-defined tasking plans, which are useful for repeated and on-demand image acquisitions at a specific area of interest such as disaster-stricken areas. These sensors are instrumental in deriving and maintaining most geospatial baseline datasets, such as road and railway networks [33,34], forest inventory [35,36], wetland delineation [37,38], digital elevation models [39-41], river and stream networks [42], building structures [43], agricultural field boundaries [44,45], and powerlines [46]. Innovative agreements such as the Single License-Multi-User Agreement (SLMA) for negotiating cheaper high-resolution data for multiple countries need to be explored in Africa. For example, SLMA between SANSA and Airbus Defense and Space (Formerly Astrium) has allowed free access of SPOT 5, 6 and 7 for all government departments, research and academic institutions since 2006. Access to SPOT 5, 6 and 7 has widened opportunities for international collaborations and meaningful participation in international projects. High- to very high-resolution data are valuable for calibration and validation, therefore presenting an added advantage and unique contribution in consortia-led and -funded projects. For example, the availability of archived and newly acquired high-resolution data at SANSA has enabled collaboration with the European Commission's Joint Research Centre (JRC), on the Global Human Settlement Layer (GHSL) initiative. The collaboration has allowed the exchange of data and techniques, which has allowed the development of National Human Settlement Layer, since 2006, to meet users' information needs, such as spatially explicit information on the status and evolution of the built environment, which is critical for planning functions 
such as town and land use planning, municipal demarcation and service provision. At a national scale, this dataset supports several legislative mandates of various government entities responsible for the implementation of laws such as Statistics Act No. 6 of 1999, Spatial Planning and Land Use Management Act No. 16 of 2013, Disaster Management Act No. 57 of 2002, Municipal Demarcation Act No. 27 of 1998, Conservation of Agricultural Resources Act No. 43 of 1983, and Electoral Act No. 73 of 1998. In addition, the information needs to support African policy frameworks such as the Program for Infrastructure Development in Africa (PIDA), which can be met through upscaling of techniques from national to continental. Also, the National SPOT mosaic dataset, distributed annually to South African institutions, has been used to generate National Land Cover data and the National Crop Boundary Layer, among other things. Essentially, innovative agreements such as SLMA, negotiated on behalf of all stakeholders, are an efficient way to access otherwise-expensive data licenses in a cost-effective and sustainable manner; thus, they are key to Africa's development and for addressing data scarcity challenges.

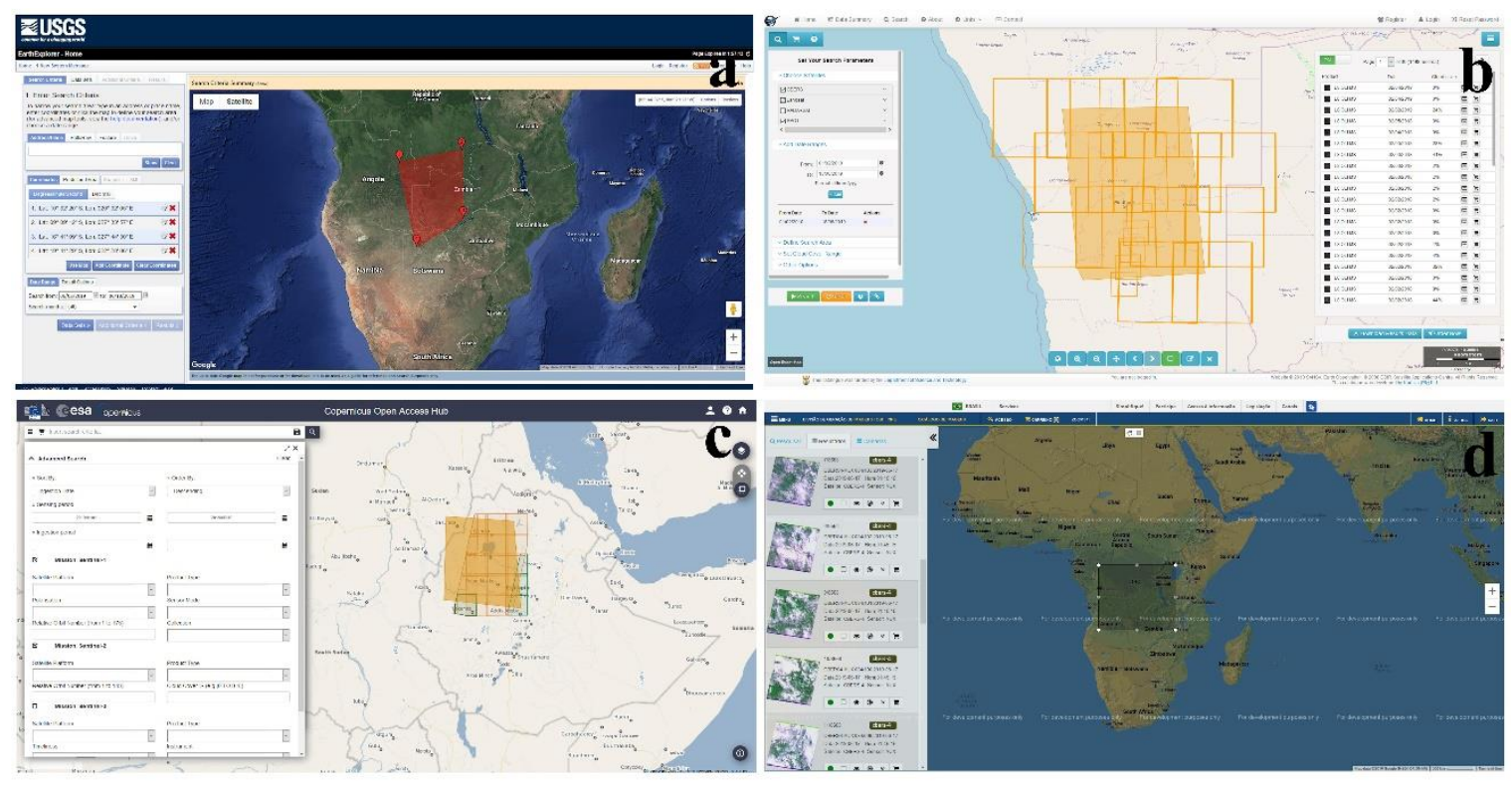

Figure 2. Examples of satellite data catalogues: (a) USGS Earth Explorer: https://earthexplorer.usgs.gov/ containing data from Landsat 1-8, Sentinel 2, ResourceSat 1-2, and a variety of AVHRR and MODIS data products; (b) SANSA catalogue: http://catalogue.sansa.org.za/search/ containing data from SumbandilaSat, SPOT 2-7, Landsat 1-8, CBERS 2-4; (c) ESA Copernicus Open Access Hub: https: //scihub.copernicus.eu/dhus/\#/home containing data from Sentinel 1-3; and (d) INPE catalogue: http://www.dgi.inpe.br/catalogo/ containing data from MODIS, Landsat 1-8, CBERS-2-4, ResourceSat 1 and 2.

On the other hand, Synthetic Aperture Radar (SAR) data has previously been 'out-of-reach' for most African countries, which is attributable to its relatively high cost when compared to optical data, as well as the complexity of the data, limited analysis tools and lack of capability to analyze the data. SAR images are useful for cloud-prone areas such as equatorial and disaster-prone areas due to their ability to acquire images in all-weather conditions and independent of light conditions. In addition, the ability to penetrate tree canopies and the surface unlocked applications such as forest disturbance, land subsidence and soil moisture mapping with improved accuracies [47]. Data from Advanced Land Observing Satellite (ALOS) 1 and 2, TerraSAR-X, ENVISAT ASAR and RADARSAT-2 have been applied for shoreline mapping [48,49], ship surveillance [50,51], oil spill monitoring [52-54], and flood extent $[55,56]$, among other things. The advent of Sentinel-1 data and increasingly open SAR data licenses for research and capacity building should allow increased research outputs and the operationalization and extension of test applications based on SAR data for monitoring soil moisture 
variability, natural disasters (such typhoons and floods), and detecting illegal activities in the oceans such as oil dumping, unlicensed fishing and mineral exploration. Therefore, developing SAR capability is of paramount importance in taking advantage of its unique properties for supporting the optimization of agriculture and ending hunger (i.e., AU-Agenda 2063, Goal 5), sustainable blue/ocean economy in Africa (i.e., AU-Agenda 2063, Goal 6), and ensuring biodiversity conservation and sustainable natural resource management (i.e., AU-Agenda 2063, Goal 7). In addition, various users need to be equipped with theoretical knowledge and practical skills to ensure a wider utilization of SAR data.

\section{Geospatial Tools for Capacity Building}

Access to software tools is one of the prerequisites for Geospatial analysis using Earth observation data. They enable effective data storage and management, data display and manipulation, and representation. For most developing countries, the cost of acquiring and managing software licenses is the main limitation to capacity building and deriving value from EO data. The advent of the Free and Open Source Software (FOSS) model has brought an unprecedented number of software tools for analyzing EO and other Geospatial datasets. The FOSS model enables collaboration, exchange of ideas, information and knowledge in an effective and efficient manner, thus promoting swift and cost-effective development and deployment of Geospatial tools. As a result, organizations such as Open Source Geospatial Foundation (OSGEO) were founded to support the collaborative development of powerful, secure and flexible geospatial software tools and promote their use. At the time of writing this manuscript, OSGEO provides a range of tools that can be categorized as content management systems, spatial databases, desktop and interactive applications, Geospatial libraries, metadata catalogues and web-based platforms (Figure 3). Similarly, major satellite data providers such as the European Space Agency (ESA), the US Geological Survey (USGS), the National Aeronautical and Space Administration (NASA), and the National Institute for Space Research (INPE), increasingly provide FOSS tools through command-line interfaces, libraries and desktop applications to ease the utilization of various datasets and formats. For example, the Sentinel Application Platform (SNAP) provides several desktop toolboxes for ingestion and manipulation of Sentinel data which is in a SAFE format. The FOSS tools provide immense opportunities for capacity building in African countries, overcoming limitations related to software license costs and limited control of workflows [57].

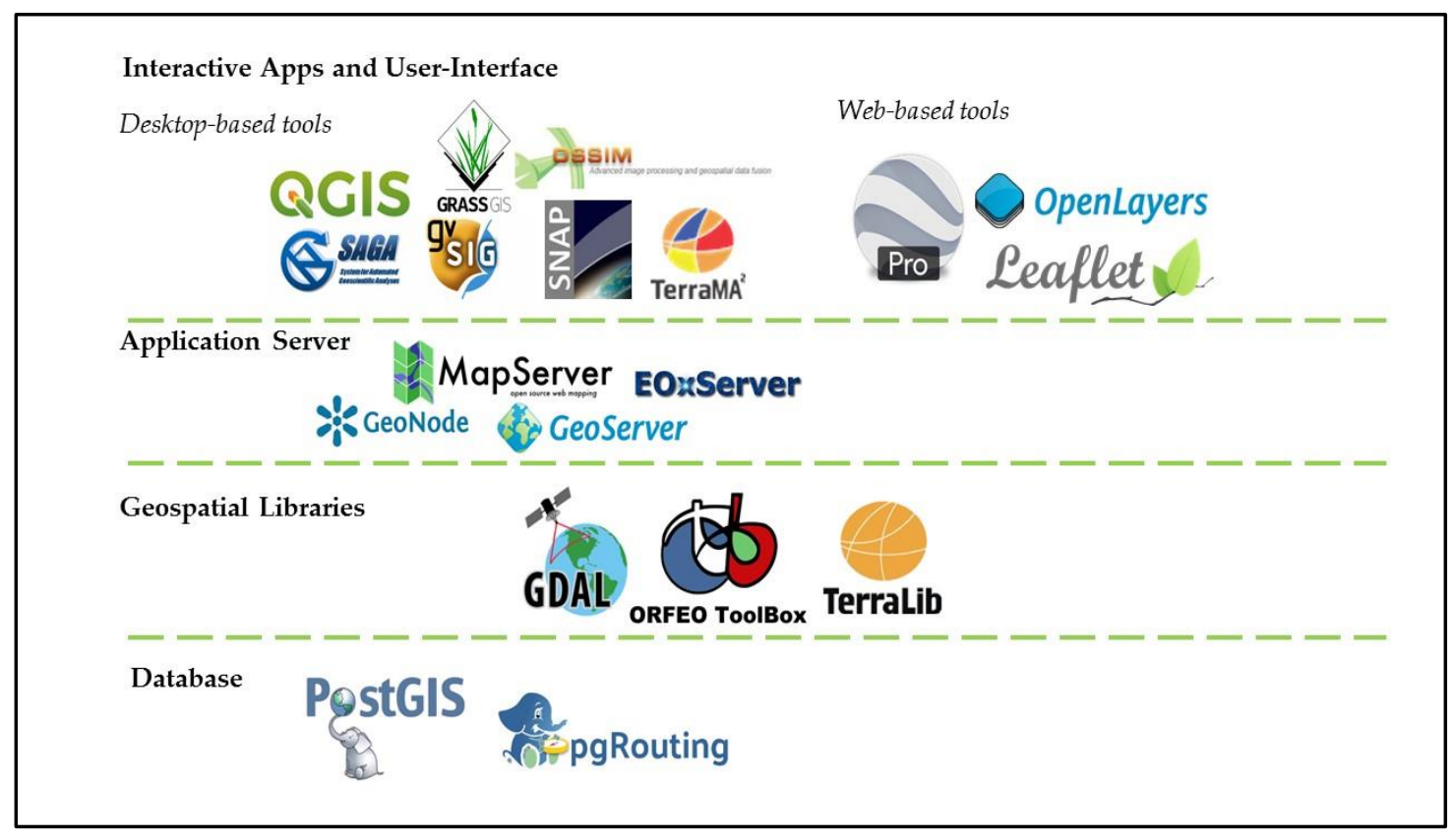

Figure 3. Some of the popular open-source software useful for capacity building in EO using data from a variety of satellite missions as well as other Geospatial data. 
However, the rate of adoption of these tools for operational purposes and in the implementation of spatial data infrastructures to support spatial planning and socio-economic development is still limited. This can be attributed to several factors, including among others; the lack of targeted marketing of FOSS tools as opposed to proprietary tools, the lack of adoption at institutions of higher learning due to lack of awareness and availability of discounted proprietary software licenses, perceived steep learning curve compounded by constant bugs and updates, the lack of comprehensive functionalities and batch processing capabilities to perform most remote sensing and GIS operations until recently, and infrequent capacity-building activities utilizing FOSS tools in Africa by African institutions. Indeed, the wider adoption of FOSS tools requires increased capacity building, targeted at technicians and practitioners. In addition, there is a growing trend towards online mapping applications operable on mobile and desktop computers, such as Google Earth, ESRI/ArcGIS Explorer and NASA World Wind. These provide simple interfaces for accessing and analyzing satellite data by non-experts such as decision and policy makers. In particular, Google Earth has been utilized in numerous applications, including, among others, land use/land cover mapping [58,59], ecological and agricultural assessment [60,61], human settlement mapping [62], and hydrological mapping [63]. Furthermore, Google Earth is known for its powerful integration of medium- to very high-resolution imagery from sensors such as Landsat $(15-30 \mathrm{~m})$ and QuickBird $(60 \mathrm{~cm})$ in a robust virtual globe environment, proving capabilities for data visualization and exploration, data capturing through on-screen digitizing, validation of land cover maps, and modelling and simulation of time-varying phenomena [64-66]. Thus, such tools are appealing to non-experts due to their free availability, ease of use, availability of simple to complex functionalites, the ability to view historical environmental conditions and the readily appreciable value and potential of EO. Consequently, tools such as Google Earth are essential for gathering support and interest for $\mathrm{EO}$ among politicians and other high-level stakeholders, demonstrating its usefulness especially in Africa, where addressing a plethora of socio-economic challenges transcends the adoption of new technologies.

The advent of cloud processing platforms such as Google Earth Engine (GEE) removes the need for costly high-end computing infrastructure for big data processing. GEE is a web-based, open-source platform that provides a global data repository of satellite time-series data from various sensors such as MODIS, Sentinel 1 and 2, Landsat, AVHRR, ALOS, etc.; cloud-based computing capabilities; and access to several processing algorithms [67]. It provides an intuitive platform for writing custom processing chains, storage, processing and analysis of data, and displaying of the results. Thus, it also removes the need for expensive commercial data processing and analysis software, essential for supporting research and development activities in developing countries. To date, the GEE platform has been utilized for research purposes in thematic areas such as land cover and use mapping [68], flood mapping and assessment [69], wetland inventory mapping [70], drought assessment [71], fire severity mapping [72], crop mapping [73] and yield estimation [74]. Although it is an open-source tool, KumarandMutanga [75] show that it is still under-utilized by most researchers in developing countries due to poor connectivity, poor data-sharing networks, and lack of awareness and technical capacity, particularly in using JavaScript and Python languages. Open-source cloud computing offers immense opportunities such as rapid development and dissemination of innovative products and services for environmental monitoring in Africa that would address the information gaps, support the achievement of AU-Agenda 2063 goals and aid reporting at a national scale. Therefore, capacity building and awareness in cloud-computing platforms such as GEE is urgently needed at various African institutions. Capacity building for academics, researchers and professionals at institutions involved in capacity building such as universities, regional training centers, and research institutes would ensure the sustainability of the transferred skills and increase awareness levels, thus increasing the utilization of these tools. 


\section{Earth Observation Products and Dissemination Platforms}

Earth observation value-added product dissemination is a fundamental task for every project to ensure that the developed products and services are optimally utilized [76]. Application-specific web-based product dissemination platforms operated by various organizations and multi-agency programs offer users the ability to search, view, analyze and download various informational products at various spatial resolutions. However, such platforms are still underutilized, mainly due to lack of awareness in the potential utility of the products to support planning, sustainable development and delivery of services [75]. Therefore, enhancing capacities in the utilization of EO-based informational products should, for example, enhance agricultural productivity in order to meet nutritional requirements of rapidly growing populations, ensure sustainable incomes for farming households, and promote sustainable agricultural practices (AU-Agenda 2063, Goals 5 and 7). For the agricultural sector, such capacities are required at different levels, including policy- and decision-makers, planners, land managers and farmers. A wide range of operational dissemination platforms are available (Figure 4), operated by various organizations such as the UN Food and Agriculture Organization (FAO), Joint Research Center (JRC), the Chinese Academy of Sciences and the United States Department of Agriculture (USDA), as well as multi-agency programs such the Group on Earth Observations (GEO), Global Agricultural Monitoring (GEOGLAM), and the Committee on Earth Observation Satellites (CEOS), among others, provide agricultural information at global, regional and national scales.

For example, GEOGLAM builds on existing national to global agricultural monitoring programs and initiatives to provide EO-derived monthly crop, rangeland and pasture condition assessments and growth monitoring through its Crop Monitor for AMIS and Crop Monitor for Early Warning bulletins (https://cropmonitor.org/) and Rangelands and Pasture Productivity (RAPP) Map (https://map.geo-rapp.org/) systems. Similarly, China's global crop-monitoring system (Crop-Watch, http://www.cropwatch.com.cn/htm/en/index.shtml) uses EO data to provide key crop production indicators such as crop area, yield and production statistics, crop condition, cropping intensity, as well as the status and severity of droughts [77]. Such information is critical for optimizing agricultural productivity, providing early warning on possible food shortages, preventing global market price volatility, and formulating effective policies $[77,78]$. In addition, the information provided by these platforms has been identified (in African Space Strategy) as fundamental to supporting African food security policy frameworks such as the Comprehensive Africa Agriculture Development Program (CAADP)(https://www.nepad.org/caadp).

These platforms are mostly based on course resolution data such as AVHRR, MODIS, SPOT-VGT, etc., thus inheriting the coarse spatial resolution and other limitations of such datasets. As a result, coarse-resolution data are more suitable for addressing the information needs of national departments such as with respect to planted area, harvesting times and area, yield estimates and production gaps, and agricultural statistics. On the other hand, course resolution products cannot meet the needs of the insurance and banking sectors. Their requirements include information on agricultural risk and crop damage for damage verification purposes to determine premiums and trigger indemnity payouts and for supporting credit or financial support decisions. On the other hand, farmers need information on crop anomalies or stress, early detection of pests and diseases, and advisory information to support irrigation scheduling, fertilizer application and stocking rates. Addressing such varying needs requires the harmonized use of multi-sensor data to take advantage of both high temporal and spatial resolutions $[74,79]$. SANSA Earth Observation Directorate takes advantage of a plethora of data available such as MODIS, Landsat, CBERS, SPOT and Sentinel to provide various agricultural monitoring products at different scales to advance food security imperatives of the country (Figure 5). SANSA focuses on the provision of multi-stakeholder relevant agricultural information in a form of maps and crop statistics informed by users' needs and within the framework of various international collaborative projects. These the include CropWatch for South Africa (CW4SA) project, in partnership with Airbus Space and Defence, funded by International Partnerships in Space Program (IPSP), 
administered by the UK Space Agency and Enhancing Food Security in African AgriCultural Systems with the support of Remote Sensing (AfriCultuReS), funded by European Commission Horizon 2020 (774652). In addition, satellite-derived biophysical parameters such as leaf area index (LAI), Fraction of Absorbed Photosynthetically Active Radiation (FAPAR), leaf chlorophyll and water content and several vegetation indices are regularly produced to monitor crop condition in both irrigated and dryland production systems in South Africa.

However, most agricultural production systems in the rest of Africa are characterized by smallholder (i.e., with area $<0.5 \mathrm{ha}$ ), dryland farming; thus, they require very detailed information, attainable through very high-resolution data such as Worldview-3. Therefore, concerted efforts to make high-resolution data available to various African countries are needed, and this is achievable through coordination by regional organizations such as AfriGEO, the African Space Agency and the African Union. Critically, timeliness of information provision are often affected by manual image processing chains involving human intervention; additionally, farmers' ability to interpret the information hinders the utility of the EO-based products for optimizing farm-level decisions. Therefore, agricultural information dissemination platforms, particularly, need to operate in a timely fashion with respect to rapidly detecting adverse conditions that may affect productivity [80]. In addition, capacity building should be tailored to and targeted at farmers (who are often ignored) to increase awareness about and develop the capability to use EO-based information in order to improve productivity and cope with agricultural risks, relevant for achieving AU-Agenda 2063 goal 5 (i.e., Modern Agriculture for increased productivity and production).

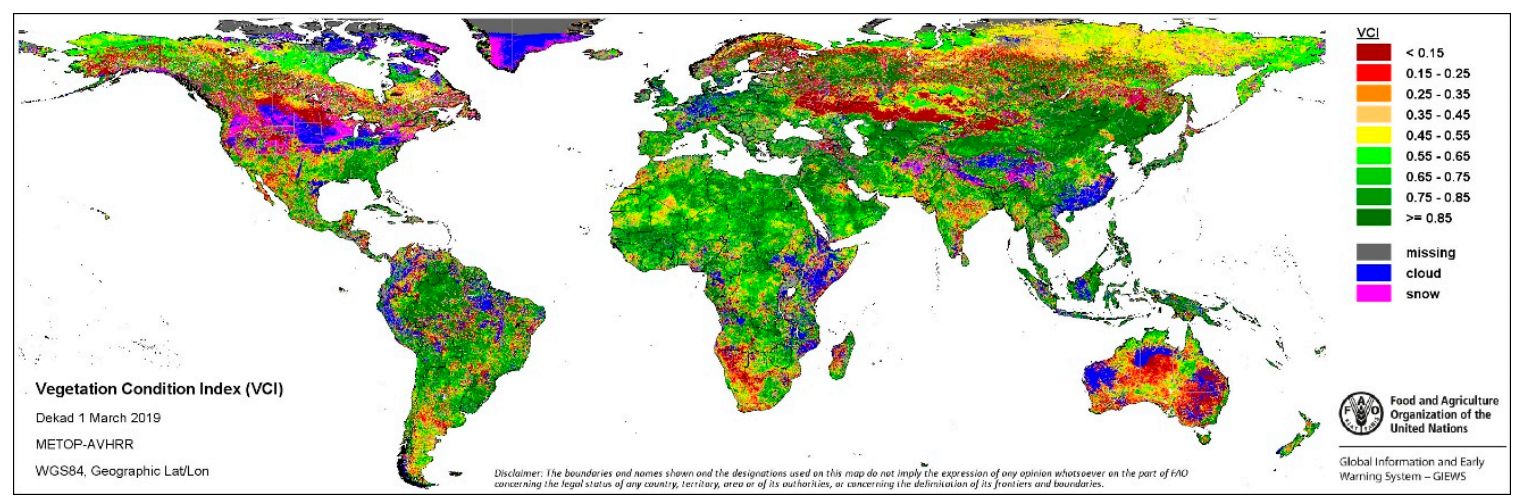

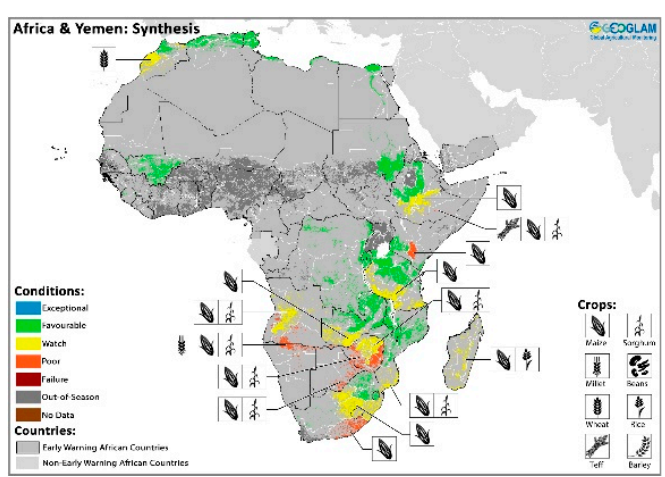

(b) (a)
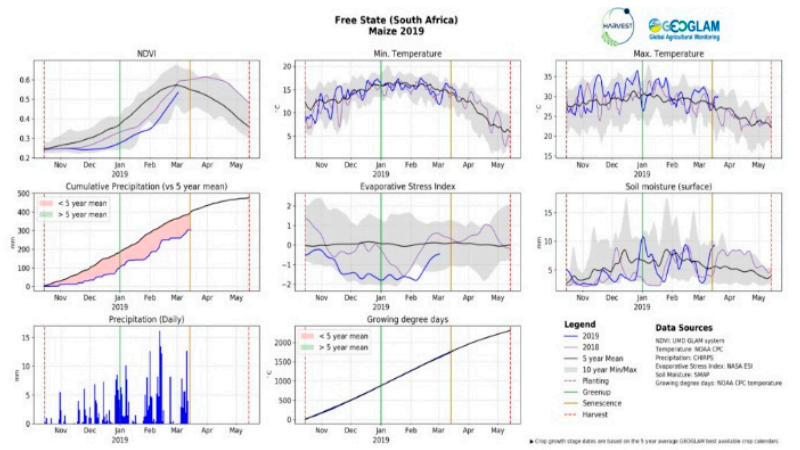

(c)

Figure 4. Cont. 


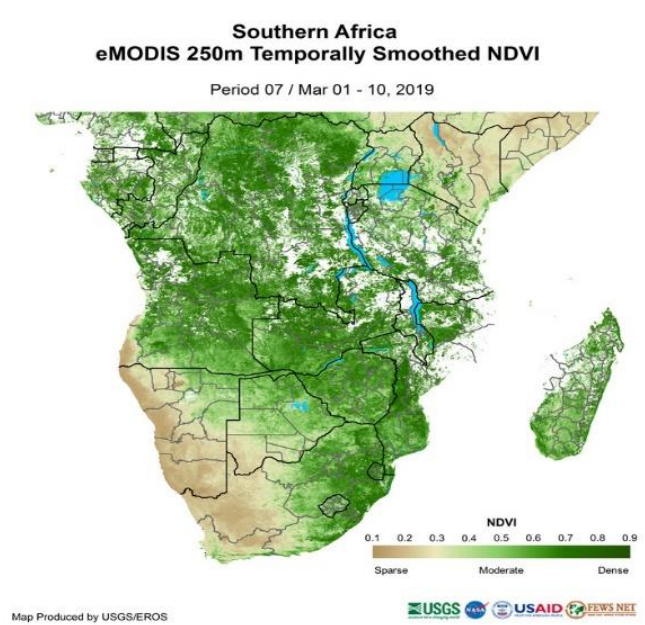

(d)

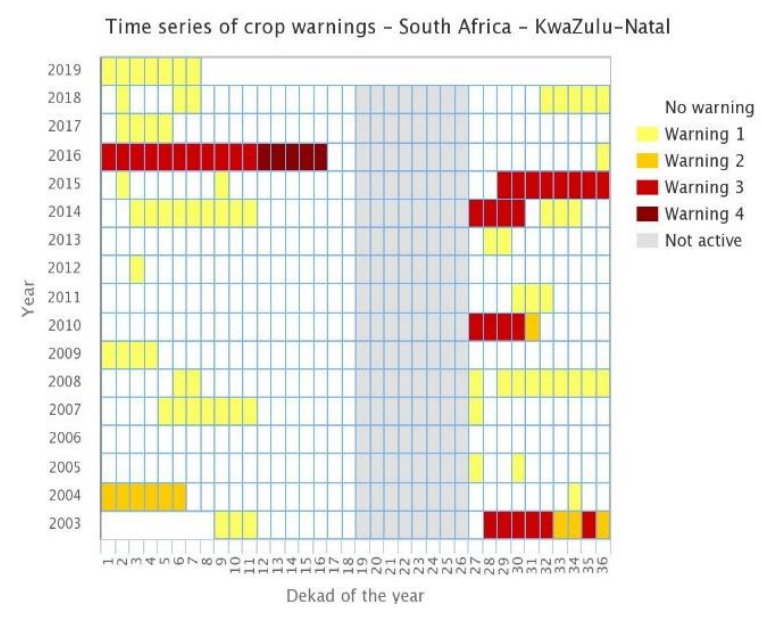

(e)

Figure 4. Examples of EO-based food security and agricultural monitoring information products provided by various operating systems. (a) Vegetation condition index (VCI) indicating current vegetation health compared to long-term historical average based on METOP-AVHRR data; (b) Crop condition map showing poor to exceptional conditions per major crop at continental scale provided by GEGLAM's Crop Monitor for Early Warning bulletins based on remotely sensed data, ground observations and field reports; (c) Agro-climatic indicators (NDVI, Minimum Temperature, Maximum Temperature, Cumulative Precipitation, Evaporative Stress Index, Soil Moisture, Daily Precipitation, and Growing Degree days) overproduction areas in Free State South Africa provided by GEOGLAM's Crop Monitor for AMIS bulletins; (d) eMODIS temporally smoothed NDVI provided by FEWS NET system every 10 days; (e) Crop warning matrix based on NDVI and Standardized Precipitation Index (SPI) provided by ASAP system.

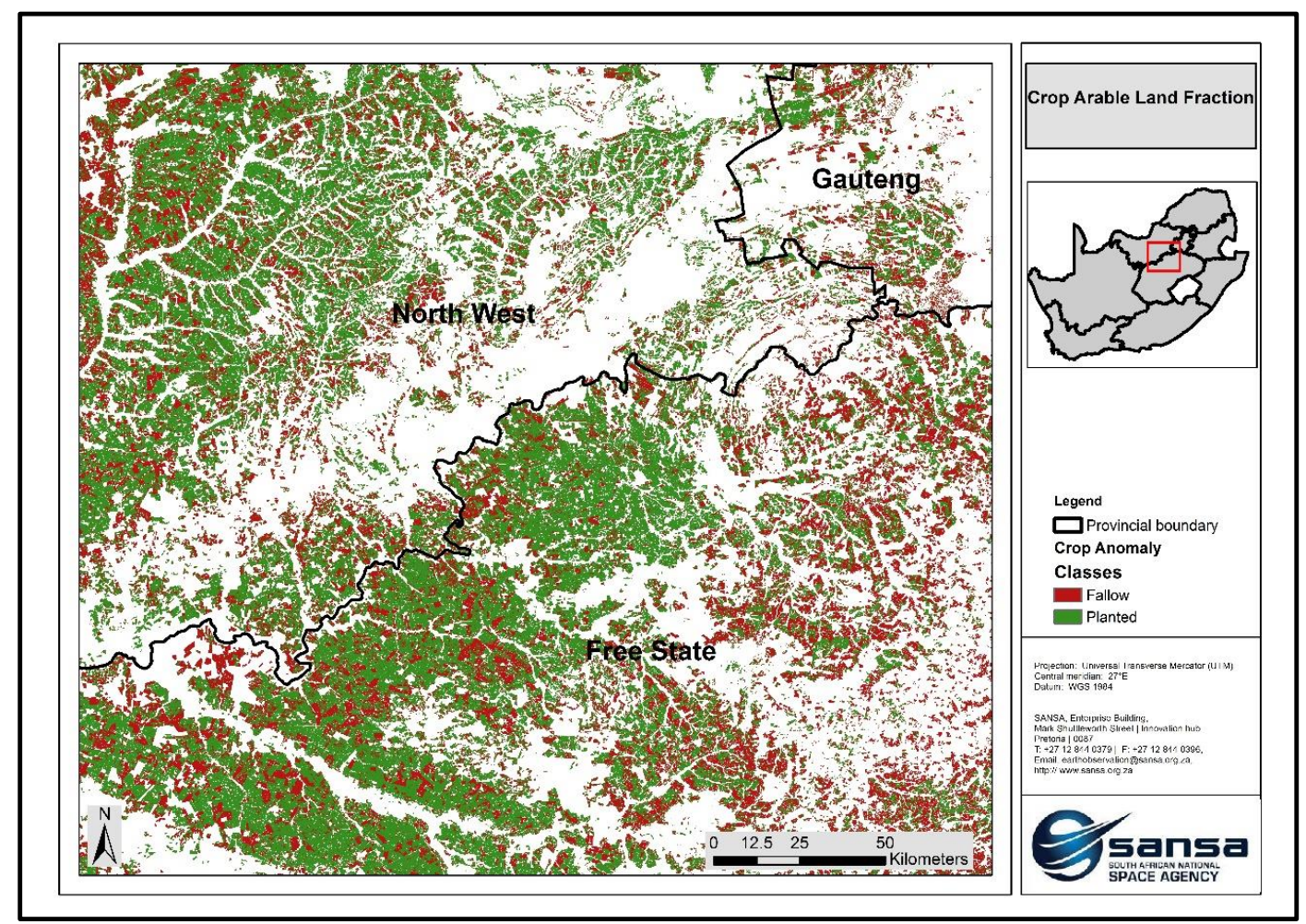

Figure 5. EO-based agricultural monitoring products developed at SANSA-based Landsat 8 OLI for national planted area monitoring. 
In addition, dissemination platforms such as Global Surface Water Explorer [20] (Figure 6) provide the global locations and distribution of water surfaces through time for the past 32 years. Pekel, Cottam, Gorelick and Belward [20] show that there has been a net increase in surface water in all continents; however, there was loss of permanent water due to river diversion, drought and unregulated water withdrawal. Thus, such detailed information is useful for informing decisions and policy for integrated water resources management from local to global scales. In the context of Africa's development, the product can support the implementation and reporting towards addressing AU-Agenda 2063 goal 7 (i.e., Environmentally sustainable and climate resilient economies and communities). Specifically, information needs on water bodies, hydrography, aquifers, wastewater, and water quality as identified by the African Space Strategy as key information to support policy frameworks such as African Water Vision 2025 [81] can be met by EO. Officials at regional offices, national and local government institutions need to be capacitated in the role of $\mathrm{EO}$ and geospatial technologies in order to support mandates and policies for sustainable integrated water management and ensure access to a safe and adequate water supply.

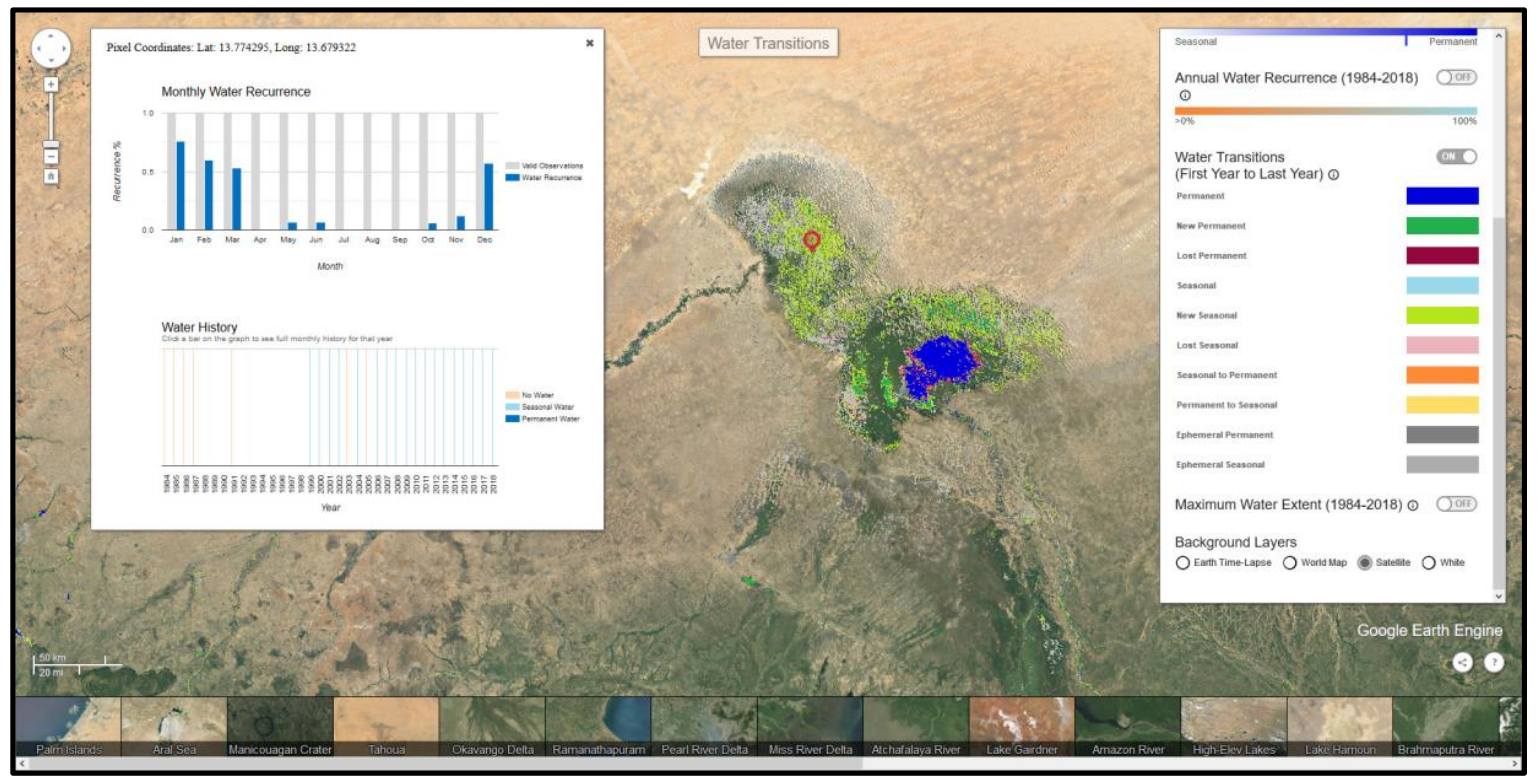

Figure 6. Global Surface Water Explorer (https://global-surface-water.appspot.com/) provides data on water occurrence (1984 to 2015), water seasonally (2014-2015), Annual Water Recurrence (1984-2015) and Water Occurrence Change Intensity (1984-2015).

At a national scale, SANSA supports the national Department of Water and Sanitation (DWS) by providing seasonal small water bodies layer (Figure 7) and water quality assessments based on Landsat 8 OLI [82,83]. The National Water Act No. 36 of 1998 (NWA) [84] and the associated National Water Resource Strategy (NWRS) [85] aim to facilitate sustainable management, conservation, and control of South Africa's water resources in order to achieve national growth, development and socio-economic priorities in an equitable and sustainable manner. Among other things, NWA emphasizes the importance of information systems for monitoring, recording, assessing and disseminating information on water resources as critical for achieving the objectives of the act. Therefore, EO-derived products can meet both qualitative and quantitative information needs such as on quantity and quality of water, water use, the health of aquatic systems, rehabilitation of water resources and atmospheric conditions that may affect water resources as outlined in NWA. Such information will be beneficial to catchment management agencies, water service authorities, and other organs of state with responsibility for water management. 


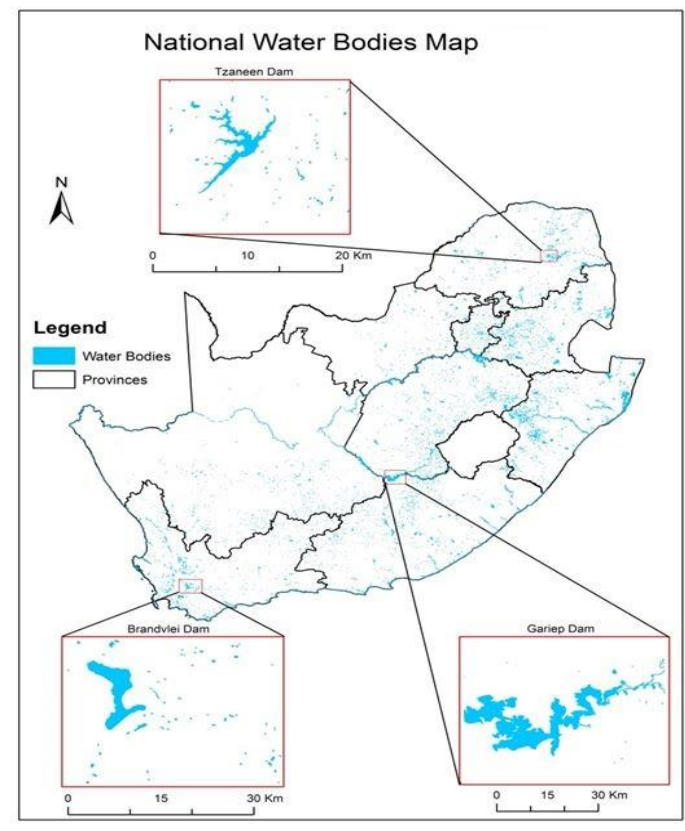

(a)

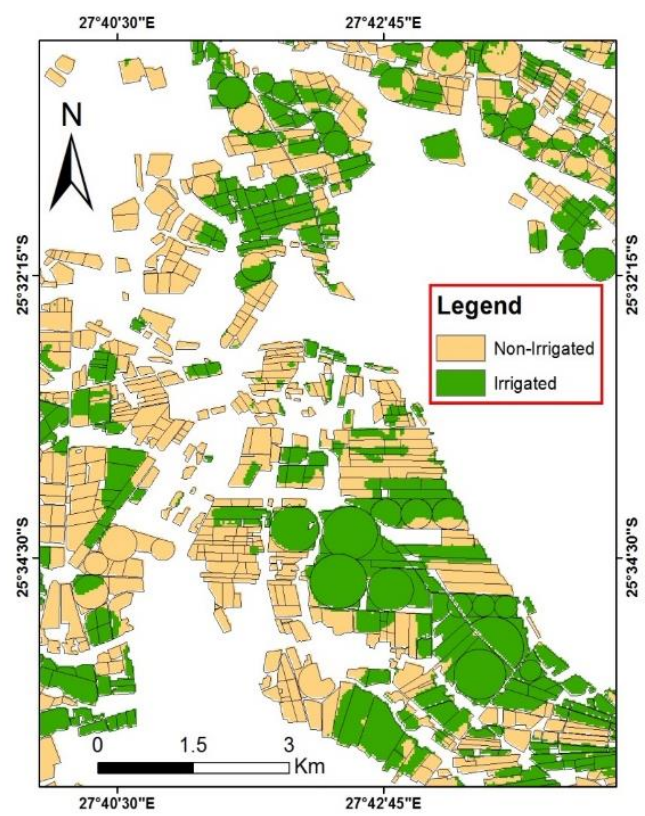

(b)

Figure 7. Water-related information for supporting integrated water resources management in South Africa. (a) The National Seasonal Water Bodies Layer and (b) irrigated and non-irrigated fields for compliance monitoring to National Water Act No. 36 of 1998 and associated regulations.

Disaster risk reduction, assessment and management is one of the global priorities informed by global policy frameworks such as the Sendai Framework for Disaster Risk Reduction 2015-2030 [86], the Paris Agreement on Climate Change and the United Nations Framework Convention on Climate Change (UNFCCC) [87]. In UN-SDG 13, Target 13.1 focuses on strengthening "resilience and adaptive capacity to climate-related hazards and natural disasters in all countries". In Africa, the frequency and intensity of climate-induced natural disasters such as floods and droughts have increased significantly, costing the affected countries billions of dollars. Consequently, AU-Agenda 2063 goal 7 prioritizes "Climate resilience and natural disasters preparedness and prevention" in the FTYIP. International initiatives such as the International Charter "Space and Major Disasters" use Earth observation data from various space agencies and commercial partners for rapid response to major disasters around the world [88]. Emerging African space agencies should aim at increasing their participation in reducing disaster risks and improving disaster response in various regions of Africa. In addition, EO and other Geospatial technologies should increasingly be exploited to support policy frameworks such as Africa Regional Strategy for Disaster Risk Reduction. Emerging space agencies should provide expertise, reference data and satellite datasets from their Earth observation missions and becoming more involved in the International Charter "Space and Major Disasters". More critically, capacity building efforts should be intensified to empower various end-users such as national disaster management centers and local governments in the use of Earth observation for disaster management.

Other product dissemination platforms that provide Earth observation data products over Africa include the Global Human Settlements Layer (GHSL, https://ghsl.jrc.ec.europa.eu) provided by the European Commission's Joint Research Council (JRC). Information on human settlements is critical because the state and growth of settlements and built-up infrastructure are closely linked to the economic and social status of nations. In fact, in addition to their functional role as places of habitation and safety, human settlements are a distinguishing feature of human civilization. On the downside, developing countries still face acute settlement challenges due to rapid population growth, urbanization and vulnerability to natural disasters. Urban sprawl and the proliferation of slums is a major problem 
confronting African countries and other developing nations. The need for timely and consistent spatial information is a common thread in all the international treaties and national plans.

\section{Strategic Partnerships for Capacity Building: Relevance for AU-Agenda 2063}

The need for partnerships has been identified as one of the priorities to achieve AU-Agenda 2063 goal 19 (Africa as a major partner in global affairs and peaceful co-existence) and concurrently UN-SDG 17 (Strengthen the means of implementation and revitalize the global partnership for sustainable development). This is also enshrined in the African Space Policy, and SANSA's strategic goals, i.e., to foster international cooperation (including with other African countries) in space-related activities. As a result, several partnerships to collaborate on various space-related activities, including capacity building, with both national (including institutions of higher learning), African (such as the Southern African Science Service Centre for Climate Change and Adaptive Land Management (SASSCAL), the Regional Centre for Mapping Resource for Development (RCMRD), and the SADC-Climate Service Centre) and international organizations (such as JRC, the UK Space Agency, JICA/JAXA and DLR) have been forged. In addition, SANSA is an active member of the Group on Earth Observations (GEO), Committee on Earth Observation Satellites (CEOS), and through the South African Earth Observation Strategy (SAEOS) participates in the Global Earth Observation System of Systems (GEOSS).

These partnerships have resulted in several collaborative capacity building projects focusing on South Africa, the SADC region and, occasionally, the rest of Africa. For example, a bilateral technical cooperation with the Japan International Cooperation Agency (JICA) and the Japanese Space Agency (JAXA) aimed at strengthening SAR remote sensing capability (including exploitation of ALOS-2 data) among South African Earth observation professionals in academia, the private sector and government, resulted in six (6) face-to-face training courses [89] held in South Africa and Japan. These training workshops provided both theoretical and practical skills in optical and SAR remote sensing, covering topics such as land cover classification, geohazard mapping, maritime, agriculture and change detection applications for land deformation/subsidence (e.g., Sinkhole) assessment using SAR Interferometry techniques. In addition, the participation in CEOS Working Group on Capacity Building and Data Democracy (WGCapD) [90] has brought several benefits for various regions in Africa, allowing knowledge sharing and collaboration between African organizations and other major international organizations such as NASA, USGS, INPE, ISRO, the European Space Agency (ESA), the United Nations Office for Outer Space Affairs (UNOOSA), and the German Aerospace Center (DLR), among others.

In the last decade, several international capacity building programs to advance human capital development on the African continent have been successfully delivered. One such program is the TIGER initiative, an international partnership program endorsed by the African Ministers' Council on Water (AMCOW), which was launched in 2002 as a response to a call of the World Summit on Sustainable Development held in Johannesburg, South Africa, in September 2002. It was launched as an urgent intervention to assist African countries in mitigating the challenges related to data acquisition, analysis and distribution of water-related Geo-information through the utilization of Earth observation data (i.e., both optical and SAR) [91]. Capacity building was considered an instrumental contribution in augmenting institutional, human and technical capacity necessary to exploit earth observation technology to support effective water resources management. As part of the TIGER program, a FOSS plugin for QGIS software, i.e., the Water Observation Information System (WOIS), was developed as part of the output [92]. The plugin has been used extensively, as it provides participants with a well-structured and easy-to-learn workflow to develop land cover, inland water bodies, inland water quality, evapotranspiration, agricultural water use, and flood monitoring products, among others, which are essential for supporting integrated water resources management. TIGER and similar capacity-building programs focusing on integrated water resources management are essential for addressing the policy frameworks such as African Water Vision 2025, the NEPAD Environment Action Plan, and support water-related decision-making at local scales towards achieving AU-Agenda 2063 
goal 7 targets to preserve at least $17 \%$ of terrestrial and inland water. Figure 8 shows participants of the TIGER capacity building workshop held in South Africa in 2015.

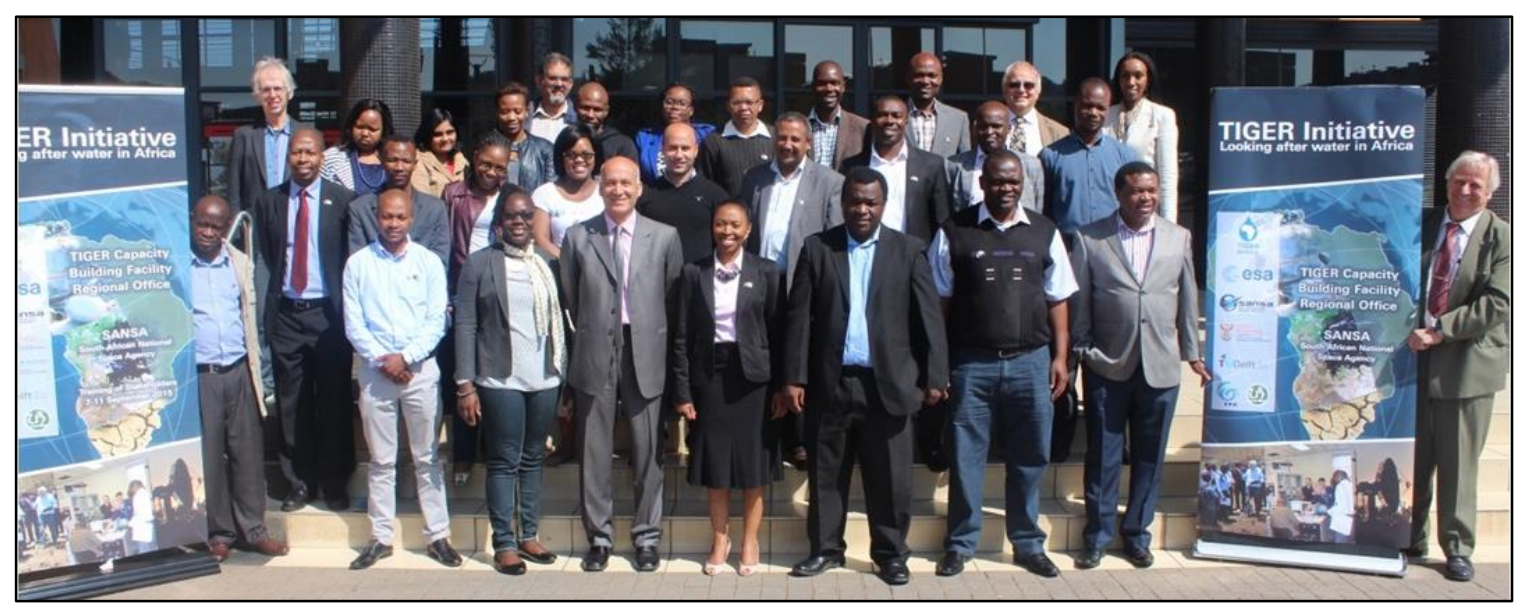

Figure 8. Participants of the TIGER training workshop in Pretoria, South Africa held from 7-11 September 2015. The participants consisted of 30 water management professionals from 10 African countries, viz. Swaziland, Egypt, Ghana, Kenya, Democratic Republic of Congo, Uganda, Ethiopia, Morocco, Madagascar and South Africa.

Recently, SANSA has partnered with the African Union Development Agency (AUDA-NEPAD) to provide, among other things, capacity building for the use of Earth observation and other geospatial tools to fast-track planning, implementation and monitoring of AU-Agenda 2063 and the UN-SDGs. As part of this objective, two training workshops were held in partnership with AUDA-NEPAD. The training workshops also exposed participants to a wide range of FOSS tools, access to free and open Earth observation data and their utility for environmental monitoring and assessment, agricultural optimization to achieve food security and monitoring of infrastructure and disaster management, as well as data capturing and management in data scarce countries. Intra-African partnerships such as these allow for building trust with member states and understand different dynamics related to data sharing. In addition, they are an efficient means of technology transfer between African countries and from well-established international institutions. Strategic partnerships in capacity building with JICA/JAXA, AUDA-NEPAD and participation in the CEOS WGCaPD and TIGER programs allowed the various regional, national, provincial and local governments, private companies, and academic institution in Africa to gain skills useful for advancing regional and national priorities in various thematic areas such as agriculture, disaster management, integrated water resources management, land management and conservation, as well as policy-making and implementation. Furthermore, capacity building models such as Training of the Trainers (ToTs) ensure that participants from various African countries continue to transfer knowledge and skills to their colleagues, as well as students studying towards degrees at historically disadvantaged universities. In addition, SANSA scientists continue to transfer their knowledge and skills through the provision of short training courses to industry professionals, students and university lecturers. As a result, of the quality of the courses, there is an increasing demand for training courses from across all spheres of government, universities, public entities and the private sector. Therefore, strategic partnerships allow for the transfer and exchange of knowledge and skills and are a clear contribution towards advancing diverse national priorities, realizing AU-Agenda 2063 aspirations and achieving UN-SDGs. For example, officials from Statistics South Africa (STATSA), an organization responsible for reporting on progress towards UN-SDGs, use knowledge and skills to improve reporting and instigate monitoring activities based on EO. Similarly, private companies such as GeoTerra Image and Southern Mapping that participated in these capacity building activities can develop innovative down-stream commercial applications stimulated by the capacity building activities, to support national government initiatives such as the 
NDP 2030. In addition, emerging space agencies can benefit from intra-African and international collaborations by leveraging available training materials developed by experts from multiple agencies, tools and data, as well as deciding to increase the number of training workshops and determine the capacity building needs, in Africa through their participation in CEOS or GEO working groups.

\section{Challenges and Opportunities for EO Capacity Building in Africa}

Perhaps the most significant challenge experienced by emerging space agencies in Africa is the relatively low level of investment in space-related activities. This is evidenced by the relatively small number of missions launched by African space agencies since the beginning of the $21^{\text {st }}$ century when compared to other developing nations in Asia, South America and India. Although initiatives such as the African Resource Monitoring Constellation (ARMC) exist [93,94], the requirement to contribute at least one satellite to the constellation in order to have access to the data from the other African missions such as from SumbandilaSat and ZaCube-1 (South Africa), Nigsat-1 and 2 (Nigeria), AlSat-1, Al-Sat 2A, and Al-Sat 2B (Algeria), EgyptSat-1 and 2 (Egypt) prohibits wider utilization of data, development of human capacities in the continent, and progress towards a self-reliant Africa. Lower investments also deter the emerging space agencies' progress towards developing required hardware infrastructure to archive, process and distribute terabytes to petabytes of data and convert the existing wealth of data into information for supporting implementation, monitoring and reporting, as well as policyand decision-making at various levels. Although cloud computing platforms such as GEE remove the need for expensive processing computers, their full exploitation is limited by the knowledge of programming using Python and JavaScript, and their sustainability and free availability in the future cannot be guaranteed. In addition, exporting of large files in GEE requires fee-based Google Cloud Storage. African institutions should leverage international funding opportunities to increase hardware capabilities and other instrumentation requirements. Capacity building in Africa has been largely dominated by face-to-face workshops, classes, conferences and seminars. This traditional means of training is essential for developing deeper relationships with users, networking between instructors, participants and facilitators, information, knowledge and multi-sectoral experiences exchange, etc. However, it is only limited to a few participants (mostly between 20 and 25 participants) due to logistical constraints (such as venue capacity and budget available), and resources (such as lab computers). In addition, lectures are only available to those attending, unless recorded and published online.

In fact, online distance learning offers prospects for addressing many of the challenges of traditional face-to-face training, by reaching hundreds to thousands of participants at once, in various locations, essential for accessing participants beyond organization's geographical reach. Several variously successful distance learning resources exist, such as NASA Applied Remote Sensing Training (ARSET, https://arset.gsfc.nasa.gov/), ESA Earth Online (https://earth.esa.int/web/guest/eo-educationand-training), ESA/University of Jena's EO-College (https://eo-college.org/), affording participants an experience as close as possible to traditional face-to-face training through live webinars and Massive Open Online Courses (MOOCs). These platforms allow binge-watching of EO content, as well as live lectures through webinars that offer active participation by writing comments directly to the course instructors and fellow students, with the ability to receive feedback, complete assignments and, upon completing the course, receive certificates of completion endorsed by the respective institutions offering the course. Although African institutions such as SANSA and RCMRD have previously contributed lectures to CEOS WGCaPD webinars, the potential of online distance learning has not been fully explored and exploited by African organizations. As such, emerging space agencies in Africa are missing out on leveraging each other's know-how, as well as those of well-established international organizations, in augmenting EO skills gaps in the continent. Perhaps one of the major limitations for the wide adoption of online distance learning, as well as adopting cloud platforms such as GEE, is the ICT challenges, particularly slow internet speed. However, the availability of policy frameworks such as the Reference Framework for Harmonization of Telecom/ICT Policies and Regulations in Africa indicates that there is vision, interest and determination to improve the current 
situation. In addition, African Space Strategy recognizes the contribution of ICT in promoting effective governance, influencing policy and regulatory frameworks. Therefore, African emerging space agencies should promote and expose users to existing platforms and also develop their own capacities in preparation for future possibilities for offering online distance education, as ICT infrastructure improves and the difference between face-to-face and online education is increasingly becoming blurred.

\section{Conclusions}

This paper discussed the potential of capacity building in Earth observation, in the context of an African emerging space agency (i.e., SANSA) for supporting the implementation, monitoring and reporting towards the achievement of AU-Agenda 2063 goals. This was done by providing an overview of available open and free satellite data, FOSS software, value-added EO-based products as well as dissemination platforms that can potentially support policy and decision making towards the achievement of national and continental priorities. Furthermore, the paper identified challenges and opportunities for wider adoption of EO and associated elements in Africa to promote sustainable development and demonstrated that strategic partnerships can enhance opportunities for African emerging space agencies. Based on the discussions in this paper, the following conclusions and recommendations were reached in the context of addressing AU-Agenda 2063 and Capacity Building.

- The availability and access to open and free EO data are critical for addressing data gaps in Africa, supporting national development and regional progress reporting on AU-Agenda 2063 imperatives. Multi-user agreements such as the one forged by SANSA and Airbus Defense and Space are an efficient and effective way of reducing the cost of higher-resolution data, thus improving its access for detailed environmental assessment and monitoring and to address data gaps. Concerted efforts are needed to adopt such models to make data available to various countries, achievable through advocacy and coordination by organizations such as AfriGEO, African Space Agency and the African Union. In addition, African emerging space agencies should adopt open data standards and policies to increase the use of data from African missions, without restrictions.

- Open-source tools should be exploited and encouraged at African institutions, thus solving technical problems, and exploring new tools should be part of the key performance indicators for technicians, technologists and professionals in government institutions, to increase tolerance to bugs and updates and ensure full exploitation to take advantage of capabilities of FOSS tools. This way, the costs of maintaining proprietary licenses can be significantly reduced.

- Emerging African space agencies with EO programs should consider the automation of manual processes to seamlessly produce and rapidly deliver EO-based informational products such as for agricultural optimization, informal settlements detection, illegal ship detection and disaster management, among other things. Cloud-based platforms such as GEE eliminate the need to download, process, and store petabytes of data, thus offering immense prospects for continent-wide research and applications development with minimal costs and equipment [75].

- The provision of EO datasets and products should be in accordance with users' needs and coupled with capacity building to ensure that the provided information is fit-for-purpose, and increase their utility by end-users. In a South African context, this strategy has resulted in increased awareness and demand for EO products and services from various spheres of government. In addition, specific attention needs to be directed towards information dissemination, considering the limitations of internet bandwidth and access in most African countries. Channels such as Unstructured Supplementary Service Data (USSD), social media and SMS should be considered in conjunction with online platforms, as well as traditional media such as local radio stations for distributing information about, for example, weather, pests and diseases and other agricultural risks facing agricultural communities. 
Overall, the discussions in this paper have implications for capacity building in EO, increased utilization of EO data and FOSS tools, adoption of open data sharing standards and policies for African EO satellite missions and intra-African and international partnerships of emerging space agencies and similar institutions for the purpose of addressing data gaps for supporting implementation, monitoring of, and reporting on AU-Agenda 2063 development imperatives.

Author Contributions: Conceptualization, Mahlatse Kganyago; formal analysis, Mahlatse Kganyago and Paidamwoyo Mhangara; writing - original draft preparation, Mahlatse Kganyago andPaidamwoyo Mhangara; writing — review and editing, Mahlatse Kganyago and Paidamwoyo Mhangara.

Funding: This research received no external funding.

Acknowledgments: We would like to acknowledge the South African National Space Agency (SANSA) Earth Observation for providing resources and material for the completion of this manuscript. These include policy briefs on Human Settlements, Food Security, and Integrated water management. We also thank SANSA Remote Sensing Scientists for providing the maps and examples used in this study. In addition, the constructive criticism provided by the anonymous reviewers and the editor that led to the improvement of this manuscript is highly appreciated.

Conflicts of Interest: The authors declare no conflict of interest. The funders had no role in the design of the study; in the collection, analyses, or interpretation of data; in the writing of the manuscript, or in the decision to publish the results.

\section{References}

1. Commission, A.U. Agenda 2063: The Africa We Want; African Union Commission: Addis Ababa, Ethiopia, 2015.

2. Organisation of African Unity. Lagos Plan of Action for the Economic Development of Africa. Available online: https://www.merit.unu.edu/wp-content/uploads/2015/01/Lagos-Plan-of-Action.pdf (accessed on 18 March 2019).

3. Vrebos, D.; Staes, J.; Vandenbroucke, T.; Johnston, R.; Muhumuza, M.; Kasabeke, C.; Meire, P. Mapping ecosystem service flows with land cover scoring maps for data-scarce regions. Ecosyst. Serv. 2015, 13, 28-40. [CrossRef]

4. Ngongondo, C.; Xu, C.-Y.; Gottschalk, L.; Alemaw, B. Evaluation of spatial and temporal characteristics of rainfall in Malawi: A case of data scarce region. Theor. Appl. Climatol. 2011, 106, 79-93. [CrossRef]

5. Currie, P.; Lay-Sleeper, E.; Fernández, J.E.; Kim, J.; Musango, J.K. Towards urban resource flow estimates in data scarce environments: The case of African cities. J. Environ. Prot. 2015, 6, 1066-1083. [CrossRef]

6. Anderson, K.; Ryan, B.; Sonntag, W.; Kavvada, A.; Friedl, L. Earth observation in service of the 2030 Agenda for Sustainable Development. Geo-Spat. Inf. Sci. 2017, 20, 77-96. [CrossRef]

7. Desconnets, J.-C.; Giuliani, G.; Guigoz, Y.; Lacroix, P.; Mlisa, A.; Noort, M.; Ray, N.; Searby, N.D. GEOCAB Portal: A gateway for discovering and accessing capacity building resources in Earth Observation. Int. J. Appl. Earth Obs. Geoinf. 2017, 54, 95-104. [CrossRef]

8. National Space Strategy. Available online: https://www.sansa.org.za/wp-content/uploads/2018/05/NationalSpace-Strategy.pdf (accessed on 22 April 2019).

9. Arino, O.; Gross, D.; Ranera, F.; Leroy, M.; Bicheron, P.; Brockman, C.; Defourny, P.; Vancutsem, C.; Achard, F.; Durieux, L. GlobCover: ESA service for global land cover from MERIS. In Proceedings of the 2007 IEEE International Geoscience and Remote Sensing Symposium, Barcelona, Spain, 23-28 July 2007; pp. 2412-2415.

10. Defourny, P.; Vancutsem, C.; Bicheron, P.; Brockmann, C.; Nino, F.; Schouten, L.; Leroy, M. GLOBCOVER: A $300 \mathrm{~m}$ global land cover product for 2005 using Envisat MERIS time series. In Proceedings of the ISPRS Commission VII Mid-Term Symposium: Remote Sensing: From Pixels to Processes, Enschede, The Netherlands, 8-11 May 2006.

11. Bartholome, E.; Belward, A.S. GLC2000: A new approach to global land cover mapping from Earth observation data. Int. J. Remote Sens. 2005, 26, 1959-1977. [CrossRef]

12. Loveland, T.R.; Reed, B.C.; Brown, J.F.; Ohlen, D.O.; Zhu, Z.; Yang, L.; Merchant, J.W. Development of a global land cover characteristics database and IGBP DISCover from $1 \mathrm{~km}$ AVHRR data. Int. J. Remote Sens. 2000, 21, 1303-1330. [CrossRef] 
13. Friedl, M.A.; McIver, D.K.; Hodges, J.C.; Zhang, X.Y.; Muchoney, D.; Strahler, A.H.; Woodcock, C.E.; Gopal, S.; Schneider, A.; Cooper, A. Global land cover mapping from MODIS: Algorithms and early results. Remote Sens. Environ. 2002, 83, 287-302. [CrossRef]

14. Friedl, M.A.; Sulla-Menashe, D.; Tan, B.; Schneider, A.; Ramankutty, N.; Sibley, A.; Huang, X. MODIS Collection 5 global land cover: Algorithm refinements and characterization of new datasets. Remote Sens. Environ. 2010, 114, 168-182. [CrossRef]

15. Levin, N.; Heimowitz, A. Mapping spatial and temporal patterns of Mediterranean wildfires from MODIS. Remote Sens. Environ. 2012, 126, 12-26. [CrossRef]

16. Davies, D.K.; Ilavajhala, S.; Wong, M.M.; Justice, C.O. Fire information for resource management system: Archiving and distributing MODIS active fire data. IEEE Trans. Geosci. Remote Sens. 2009, 47, 72-79. [CrossRef]

17. Gatebe, C.; Ichoku, C.; Poudyal, R.; Román, M.; Wilcox, E. Surface albedo darkening from wildfires in northern sub-Saharan Africa. Environ. Res. Lett. 2014, 9, 065003. [CrossRef]

18. Bertels, L.; Smets, B.; Wolfs, D. Dynamic water surface detection algorithm applied on PROBA-V multispectral data. Remote Sens. 2016, 8, 1010. [CrossRef]

19. Dube, T.; Mutanga, O.; Seutloali, K.; Adelabu, S.; Shoko, C. Water quality monitoring in sub-Saharan African lakes: A review of remote sensing applications. Afr. J. Aquat. Sci. 2015, 40, 1-7. [CrossRef]

20. Pekel, J.-F.; Cottam, A.; Gorelick, N.; Belward, A.S. High-resolution mapping of global surface water and its long-term changes. Nature 2016, 540, 418. [CrossRef] [PubMed]

21. Proud, S.R.; Fensholt, R.; Rasmussen, L.V.; Sandholt, I. Rapid response flood detection using the MSG geostationary satellite. Int. J. Appl. Earth Obs. Geoinf. 2011, 13, 536-544. [CrossRef]

22. Bryant, R.; Rainey, M. Investigation of flood inundation on playas within the Zone of Chotts, using a time-series of AVHRR. Remote Sens. Environ. 2002, 82, 360-375. [CrossRef]

23. Eerens, H.; Haesen, D.; Rembold, F.; Urbano, F.; Tote, C.; Bydekerke, L. Image time series processing for agriculture monitoring. Environ. Model. Softw. 2014, 53, 154-162. [CrossRef]

24. Meroni, M.; Fasbender, D.; Balaghi, R.; Dali, M.; Haffani, M.; Haythem, I.; Hooker, J.; Lahlou, M.; Lopez-Lozano, R.; Mahyou, H. Evaluating NDVI data continuity between SPOT-VEGETATION and PROBA-V missions for operational yield forecasting in North African countries. IEEE Trans. Geosci. Remote Sens. 2016, 54, 795-804. [CrossRef]

25. Vintrou, E.; Desbrosse, A.; Bégué, A.; Traoré, S.; Baron, C.; Seen, D.L. Crop area mapping in West Africa using landscape stratification of MODIS time series and comparison with existing global land products. Int. J. Appl. Earth Obs. Geoinf. 2012, 14, 83-93. [CrossRef]

26. Zhang, X.; Friedl, M.A.; Schaaf, C.B. Global vegetation phenology from Moderate Resolution Imaging Spectroradiometer (MODIS): Evaluation of global patterns and comparison with in situ measurements. J. Geophys. Res. Biogeosci. 2006, 111. [CrossRef]

27. Muchoney, D.M.; Williams, M. Building a 2010 biodiversity conservation data baseline: Contributions of the Group on Earth Observations. Ecol. Res. 2010, 25, 937-946. [CrossRef]

28. Eklundh, L.; Olsson, L. Vegetation index trends for the African Sahel 1982-1999. Geophys. Res. Lett. $2003,30$. [CrossRef]

29. Swinnen, E.; Veroustraete, F. Extending the SPOT-VEGETATION NDVI time series (1998-2006) back in time with NOAA-AVHRR data (1985-1998) for southern Africa. IEEE Trans. Geosci. Remote Sens. 2008, 46, 558-572. [CrossRef]

30. Toukiloglou, P. Comparison of AVHRR, MODIS and VEGETATION for Land Cover Mapping and Drought Monitoring at $1 \mathrm{~km}$ Spatial Resolution. Ph.D. Thesis, Cranfield University, Cranfield, UK, 2007.

31. Africa Regional Data Cube. Available online: http://www.data4sdgs.org/index.php/initiatives/africa-regionaldata-cube (accessed on 2 March 2019).

32. Digital Earth Africa. Available online: https://www.ga.gov.au/_data/assets/pdf_file/0008/73376/DigitalEarth-Africa.pdf (accessed on 12 April 2019).

33. Shahi, K.; Shafri, H.Z.; Taherzadeh, E.; Mansor, S.; Muniandy, R. A novel spectral index to automatically extract road networks from WorldView-2 satellite imagery. Egypt. J. Remote Sens. Space Sci. 2015, 18, 27-33. [CrossRef]

34. Yan, Q.; Zhang, J.-X.; Qiu, Z.-C.; Gao, W.-J. Capability of Spot 5 Imagery in Surveying and Mapping. Available online: http://en.cnki.com.cn/Article_en/CJFDTotal-CHKD200504031.htm (accessed on 24 March 2019). 
35. De Wulf, R.R.; Goossens, R.E.; de Roover, B.P.; Borry, F.C. Extraction of forest stand parameters from panchromatic and multispectral SPOT-1 data. Int. J. Remote Sens. 1990, 11, 1571-1588. [CrossRef]

36. Peerbhay, K.Y.; Mutanga, O.; Ismail, R. Investigating the capability of few strategically placed Worldview-2 multispectral bands to discriminate forest species in KwaZulu-Natal, South Africa. IEEE J. Sel. Top. Appl. Earth Obs. Remote Sens. 2014, 7, 307-316. [CrossRef]

37. Mahdavi, S.; Salehi, B.; Granger, J.; Amani, M.; Brisco, B.; Huang, W. Remote sensing for wetland classification: A comprehensive review. Gisci. Remote Sens. 2018, 55, 623-658. [CrossRef]

38. Davranche, A.; Lefebvre, G.; Poulin, B. Wetland monitoring using classification trees and SPOT-5 seasonal time series. Remote Sens. Environ. 2010, 114, 552-562. [CrossRef]

39. Krupnik, A. Accuracy assessment of automatically derived digital elevation models from SPOT images. Photogramm. Eng. Remote Sens. 2000, 66, 1017-1023.

40. Day, T.; Muller, J.P. Quality assessment of digital elevation models produced by automatic stereomatchers from SPOT image pairs. Photogramm. Rec. 1988, 12, 797-808. [CrossRef]

41. Poon, J.; Fraser, C.S.; Chunsun, Z.; Li, Z.; Gruen, A. Quality assessment of digital surface models generated from IKONOS imagery. Photogramm. Rec. 2005, 20, 162-171. [CrossRef]

42. Fairfield, J.; Leymarie, P. Drainage networks from grid digital elevation models. Water Resour. Res. 1991, 27, 709-717. [CrossRef]

43. Ekhtari, N.; Zoej, M.J.V.; Sahebi, M.R.; Mohammadzadeh, A. Automatic building extraction from LIDAR digital elevation models and WorldView imagery. J. Appl. Remote Sens. 2009, 3, 033571. [CrossRef]

44. McCarty, J.; Neigh, C.; Carroll, M.; Wooten, M. Extracting smallholder cropped area in Tigray, Ethiopia with wall-to-wall sub-meter WorldView and moderate resolution Landsat 8 imagery. Remote Sens. Environ. 2017, 202, 142-151. [CrossRef]

45. Rydberg, A.; Borgefors, G. Integrated method for boundary delineation of agricultural fields in multispectral satellite images. IEEE Trans. Geosci. Remote Sens. 2001, 39, 2514-2520. [CrossRef]

46. Matikainen, L.; Lehtomäki, M.; Ahokas, E.; Hyyppä, J.; Karjalainen, M.; Jaakkola, A.; Kukko, A.; Heinonen, T. Remote sensing methods for power line corridor surveys. ISPRS J. Photogramm. Remote Sens. 2016, 119, 10-31. [CrossRef]

47. Hong, S.-H.; Kim, H.-O.; Wdowinski, S.; Feliciano, E. Evaluation of polarimetric SAR decomposition for classifying wetland vegetation types. Remote Sens. 2015, 7, 8563-8585. [CrossRef]

48. Billa, L.; Pradhan, B. Semi-automated procedures for shoreline extraction using single RADARSAT-1 SAR image. Estuar. Coast. Shelf Sci. 2011, 95, 395-400.

49. Yeremy, M.L.; Beaudoin, A.; Beaudoin, J.D.; Walter, G.M. Global Shoreline Mapping from an Airborne Polarimetric SAR: Assessment for RADARSAT 2 Polarimetric Modes; DEFENCE RESEARCH ESTABLISHMENT OTTAWA (ONTARIO): Fort Belvoir, VA, USA, 2001.

50. Brusch, S.; Lehner, S.; Fritz, T.; Soccorsi, M.; Soloviev, A.; van Schie, B. Ship surveillance with TerraSAR-X. IEEE Trans. Geosci. Remote Sens. 2011, 49, 1092-1103. [CrossRef]

51. Zhao, Z.; Ji, K.; Xing, X.; Zou, H.; Zhou, S. Ship surveillance by integration of space-borne SAR and AIS-review of current research. J. Navig. 2014, 67, 177-189. [CrossRef]

52. Mdakane, L.W.; Kleynhans, W. An image-segmentation-based framework to detect oil slicks from moving vessels in the southern african oceans using SAR imagery. IEEE J. Sel. Top. Appl. Earth Obs. Remote Sens. 2017, 10, 2810-2818. [CrossRef]

53. Solberg, A.H.; Brekke, C.; Husoy, P.O. Oil spill detection in Radarsat and Envisat SAR images. IEEE Trans. Geosci. Remote Sens. 2007, 45, 746-755. [CrossRef]

54. Rouault, M.; Johannessen, J.; Collard, F.; Bernard, S. Synthetic aperture radar products for the African marine environment. S. Afr. J. Sci. 2009, 105, 85-86. [CrossRef]

55. Rebelo, L.-M. Eco-hydrological characterization of inland wetlands in Africa using L-band SAR. IEEE J. Sel. Top. Appl. Earth Obs. Remote Sens. 2010, 3, 554-559. [CrossRef]

56. Long, S.; Fatoyinbo, T.E.; Policelli, F. Flood extent mapping for Namibia using change detection and thresholding with SAR. Environ. Res. Lett. 2014, 9, 035002. [CrossRef]

57. Ciolli, M.; Federici, B.; Ferrando, I.; Marzocchi, R.; Sguerso, D.; Tattoni, C.; Vitti, A.; Zatelli, P. FOSS Tools and Applications for Education in Geospatial Sciences. ISPRS Int. J. Geo-Inf. 2017, 6, 225. [CrossRef] 
58. Gong, P.; Wang, J.; Yu, L.; Zhao, Y.; Zhao, Y.; Liang, L.; Niu, Z.; Huang, X.; Fu, H.; Liu, S. Finer resolution observation and monitoring of global land cover: First mapping results with Landsat TM and ETM+ data. Int. J. Remote Sens. 2013, 34, 2607-2654. [CrossRef]

59. Hu, Q.; Wu, W.; Xia, T.; Yu, Q.; Yang, P.; Li, Z.; Song, Q. Exploring the use of Google Earth imagery and object-based methods in land use/cover mapping. Remote Sens. 2013, 5, 6026-6042. [CrossRef]

60. Guan, X.; Huang, C.; Liu, G.; Meng, X.; Liu, Q. Mapping rice cropping systems in Vietnam using an NDVI-based time-series similarity measurement based on DTW distance. Remote Sens. 2016, 8, 19. [CrossRef]

61. Jin, N.; Tao, B.; Ren, W.; Feng, M.; Sun, R.; He, L.; Zhuang, W.; Yu, Q. Mapping irrigated and rainfed wheat areas using multi-temporal satellite data. Remote Sens. 2016, 8, 207. [CrossRef]

62. Ghaffarian, S. Automatic building detection based on Purposive FastICA (PFICA) algorithm using monocular high resolution Google Earth images. ISPRS J. Photogramm. Remote Sens. 2014, 97, 152-159. [CrossRef]

63. Ibrahim-Bathis, K.; Ahmed, S. Geospatial technology for delineating groundwater potential zones in Doddahalla watershed of Chitradurga district, India. Egypt. J. Remote Sens. Space Sci. 2016, 19, 223-234. [CrossRef]

64. Liang, J.; Gong, J.; Li, W. Applications and impacts of Google Earth: A decadal review (2006-2016). ISPRS J. Photogramm. Remote Sens. 2018, 146, 91-107. [CrossRef]

65. Yu, L.; Gong, P. Google Earth as a virtual globe tool for Earth science applications at the global scale: Progress and perspectives. Int. J. Remote Sens. 2012, 33, 3966-3986. [CrossRef]

66. Goodchild, M.F. The use cases of digital earth. Int. J. Digit. Earth 2008, 1, 31-42. [CrossRef]

67. Gorelick, N.; Hancher, M.; Dixon, M.; Ilyushchenko, S.; Thau, D.; Moore, R. Google Earth Engine: Planetary-scale geospatial analysis for everyone. Remote Sens. Environ. 2017, 202, 18-27. [CrossRef]

68. Johansen, K.; Phinn, S.; Taylor, M. Mapping woody vegetation clearing in Queensland, Australia from Landsat imagery using the Google Earth Engine. Remote Sens. Appl. Soc. Environ. 2015, 1, 36-49. [CrossRef]

69. Liu, C.-C.; Shieh, M.-C.; Ke, M.-S.; Wang, K.-H. Flood prevention and emergency response system powered by Google Earth Engine. Remote Sens. 2018, 10, 1283. [CrossRef]

70. Mahdianpari, M.; Salehi, B.; Mohammadimanesh, F.; Homayouni, S.; Gill, E. The First Wetland Inventory Map of Newfoundland at a Spatial Resolution of $10 \mathrm{~m}$ Using Sentinel-1 and Sentinel-2 Data on the Google Earth Engine Cloud Computing Platform. Remote Sens. 2019, 11, 43. [CrossRef]

71. Sazib, N.; Mladenova, I.; Bolten, J. Leveraging the Google Earth Engine for Drought Assessment Using Global Soil Moisture Data. Remote Sens. 2018, 10, 1265. [CrossRef]

72. Parks, S.; Holsinger, L.; Voss, M.; Loehman, R.; Robinson, N. Mean composite fire severity metrics computed with Google Earth Engine offer improved accuracy and expanded mapping potential. Remote Sens. 2018, 10, 879. [CrossRef]

73. Xiong, J.; Thenkabail, P.; Tilton, J.; Gumma, M.; Teluguntla, P.; Oliphant, A.; Congalton, R.; Yadav, K.; Gorelick, N. Nominal 30-m cropland extent map of continental Africa by integrating pixel-based and object-based algorithms using Sentinel-2 and Landsat-8 data on Google Earth Engine. Remote Sens. 2017, 9 , 1065. [CrossRef]

74. He, M.; Kimball, J.; Maneta, M.; Maxwell, B.; Moreno, A.; Beguería, S.; Wu, X. Regional crop gross primary productivity and yield estimation using fused landsat-MODIS data. Remote Sens. 2018, 10, 372. [CrossRef]

75. Kumar, L.; Mutanga, O. Google Earth Engine Applications Since Inception: Usage, Trends, and Potential. Remote Sens. 2018, 10, 1509. [CrossRef]

76. L'Astorina, A.; Tomasoni, I.; Basoni, A.; Carrara, P. Beyond the dissemination of Earth Observation research: Stakeholders' and users' involvement in project co-design. J. Sci. Commun. 2015, 14, C03. [CrossRef]

77. Wu, B.; Meng, J.; Li, Q.; Yan, N.; Du, X.; Zhang, M. Remote sensing-based global crop monitoring: Experiences with China's CropWatch system. Int. J. Digit. Earth 2014, 7, 113-137. [CrossRef]

78. Becker-Reshef, I.; Justice, C.; Sullivan, M.; Vermote, E.; Tucker, C.; Anyamba, A.; Small, J.; Pak, E.; Masuoka, E.; Schmaltz, J. Monitoring global croplands with coarse resolution earth observations: The Global Agriculture Monitoring (GLAM) project. Remote Sens. 2010, 2, 1589-1609. [CrossRef]

79. Claverie, M.; Ju, J.; Masek, J.G.; Dungan, J.L.; Vermote, E.F.; Roger, J.-C.; Skakun, S.V.; Justice, C. The Harmonized Landsat and Sentinel-2 surface reflectance data set. Remote Sens. Environ. 2018, 219, $145-161$. [CrossRef] 
80. Atzberger, C. Advances in remote sensing of agriculture: Context description, existing operational monitoring systems and major information needs. Remote Sens. 2013, 5, 949-981. [CrossRef]

81. African Union. African Space Strategy. Available online: https:/au.int/sites/default/files/newsevents/ workingdocuments/33178-wd-african_space_strategy_-_st20445_e_original.pdf (accessed on 15 April 2019).

82. Malahlela, O.E. Inland waterbody mapping: Towards improving discrimination and extraction of inland surface water features. Int. J. Remote Sens. 2016, 37, 4574-4589. [CrossRef]

83. Malahlela, O.E.; Oliphant, T.; Tsoeleng, L.T.; Mhangara, P. Mapping chlorophyll-a concentrations in a cyanobacteria-and algae-impacted Vaal Dam using Landsat 8 OLI data. S. Afr. J. Sci. 2018, 114, 1-9. [CrossRef]

84. Republic of South Africa. National Water Act Act No 36 of 1998. Available online: http://www.dwaf.gov.za/ Documents/Legislature/nw_act/NWA.htm (accessed on 21 March 2019).

85. National Water Resource Strategy. Available online: http://www.dwa.gov.za/documents/Other/Strategic\% 20Plan/NWRS2-Final-email-version.pdf (accessed on 22 April 2019).

86. Nations, U. Sendai Framework for Disaster Risk Reduction 2015-2030; United Nations: San Francisco, CA, USA, 2015.

87. Protocol, K. United Nations Framework Convention on Climate Change. Available online: http://www. globaldialoguefoundation.org/files/ENV.2009-jun.unframeworkconventionclimate.pdf (accessed on 15 April 2019).

88. Bessis, J.-L.; Bequignon, J.; Mahmood, A. The international charter "space and major disasters" initiative. Acta Astronaut. 2004, 54, 183-190. [CrossRef]

89. SANSA and the Japan International Cooperation Agency Conduct Training in Agricultural Crop Monitoring and Crop Yield Estimation to Government Officials. Available online: https://www.sansa.org.za/2017/05/23/sansa-and-the-japan-international-cooperation-agency-conducttraining-in-agricultural-crop-monitoring-and-crop-yield-estimation-to-government-officials/ (accessed on 18 March 2019).

90. Committee on Earth Observation Satellites (CEOS). The Working Group on Capacity Building and Data Democracy. Available online: http://ceos.org/ourwork/workinggroups/wgcapd/ (accessed on 20 March 2019).

91. Fernandez-Prieto, D.; Palazzo, F. The role of Earth observation in improving water governance in Africa: ESA's TIGER initiative. Hydrogeol. J. 2007, 15, 101-104. [CrossRef]

92. Walli, A.; Tøttrup, C.; Naeimi, V.; Bauer-Gottwein, P.; Bila, M.; Mufeti, P.; Tumbulto, J.; Rajah, C.; Moloele, L.; Koetz, B. TIGER-NET-Enabling an earth observation capacity for integrated water resource management in Africa. In Proceedings of the ESA Living Planet Symposium, Edinburgh, UK, 9-13 September 2013.

93. Ansdell, M.; Delgado, L.; Hendrickson, D. Analyzing the Development Paths of Emerging Spacefaring Nations: Opportunities or Challenges for Space Sustainability? George Washington University: Washington, DC, USA, 2011.

94. Tella, O. Space as a Fulcrum of Nigeria's External Relations and Regional Hegemony. Space Policy 2018, 46, 46-52. [CrossRef]

(C) 2019 by the authors. Licensee MDPI, Basel, Switzerland. This article is an open access article distributed under the terms and conditions of the Creative Commons Attribution (CC BY) license (http://creativecommons.org/licenses/by/4.0/). 